\title{
Changes in productivity, psychological wellbeing and physical wellbeing from working in a 'green' building
}

\author{
Andrew Thatcher* and Karen Milner \\ Psychology Department, University of the Witwatersrand, Johannesburg, South Africa
}

Received 4 October 2012

Accepted 8 August 2013

\begin{abstract}
.
BACKGROUND: Based on improvements in indoor environmental quality claims are that 'green' buildings are healthier and promote greater productivity than conventional buildings. However, the empirical evidence over the last decade has been inconclusive, usually with flawed study designs.

OBJECTIVE: This study explored whether a 'green' building leads to a healthier, more productive work environment.

METHODS: A one-year, longitudinal comparison of two groups of employees of a large commercial bank; a group that moved into a GreenStar-accredited building and a group that stayed in a conventional building, was conducted. Measures of psychological wellbeing, physical wellbeing, productivity, and perceptions of the physical environment were taken before the move, six months later, and one year later.

RESULTS: Results indicate that the 'green' building group had significantly increased self-reported productivity and physical wellbeing. The perceptions of the physical work environment indicate that respondents in the 'green' building group experienced significant air quality improvements (specifically, reduced stale air, better ventilation, improved air movement, reduced humidity, and conditions that were not too drafty) but perceived the lighting conditions as dimmer.
\end{abstract}

CONCLUSION: Despite positive findings 'green' building rating tools require amendment to focus on those qualities that actually lead to improved wellbeing and productivity.

Keywords: GreenStar accreditation, self-reported productivity, absenteeism, workplace indoor environmental quality

\section{Introduction}

The term 'green ergonomics' has only recently been defined [1]. Hedge [2] first used the term in the title of his article to the Human Factors and Ergonomics Society (HFES) Bulletin to introduce the contribution of ergonomics to 'green' building design. Hanson [3] used the term for her Donald Broadbent lecture at the Institute of Human Factors and Ergonomics conference

*Corresponding author: Andrew Thatcher, Psychology Department, University of the Witwatersrand, WITS, 2050, South Africa. Tel.: +27 11717 4533; Fax: +27 86553 4907; E-mail: andrew. thatcher@wits.ac.za. in 2010, but did not specifically define the term. She suggested that 'green ergonomics' could look at the design of: 'green' jobs, low energy systems and products, transport systems and vehicles, buildings and urban environments, communication systems, and retail systems. Thatcher [1] defined 'green ergonomics' as ensuring human and natural system wellbeing through understanding the bi-directional relationships between natural systems and human systems. Using this definition, 'green' buildings should be built to ensure the wellbeing of natural systems as well as ensuring the wellbeing of the building's occupants. Using a different term, Steimle and Zink [4] defined 'human factors and sustainable development' as a broader concept that invites ergonomics to include economic, so- 
cial, and environmental factors into the ergonomics design process. However, the term 'human factors and sustainable development' has been widely interpreted in recent years and is still gaining theoretical stability [5]. Within this broader definition, 'green ergonomics' might therefore be considered to be primarily concerned with the impact of ergonomics on ameliorating the negative impacts of humans on the natural environment, although it must be acknowledged that this definition is not yet widely entrenched or accepted. This study looks at one of the possible contributions that 'green ergonomics' can make; specifically the design and operation of environmentally sustainable 'green' buildings. Several authors $[6,7]$ have noted a number of different points at which ergonomics principles and methods can contribute to improving 'green' building design. These include: the ergonomics of 'green' building construction [8,9] and building maintenance, ergonomics factors related to demolition [7], designing for sustainable work that ensures comfort and safety, understanding how 'green' buildings are used by their occupants, and understanding how 'green' building design innovations influence actual occupant behaviour. This study falls into the latter category; understanding how 'green' building design aspects such as environmental comfort, personal control, and energy efficiency impact on the wellbeing and productivity of building occupants.

\section{1. 'Green' buildings}

The US Environmental Protection Agency [10] defines 'green' buildings as "the practice of creating structures and using processes that are environmentally responsible and resource-efficient throughout a building's life-cycle". This is achieved through efficiently using resources (e.g. energy, water, building materials, etc.), ensuring occupant health and increasing productivity, and reducing the impact of outputs on the environment (e.g. waste reduction) [10]. This means taking a holistic approach that takes into account building materials, building design itself, and the need for sustainable work. Qualifying as a 'green' building usually involves some form of rating against objective criteria. Internationally, the last two decades have seen the emergence of a number of voluntary benchmarks and standards to guide the promotion, design and operation of 'green' buildings. Such rating tools include the British Establishment Environmental Assessment Method (BREEAM), the Leadership in Energy and Environmental Design (LEED), GreenStar Australia,
GreenStar South Africa, and the National Australian Built Environment Rating System (NABERS) amongst a number of other rating tools. 'Green' building rating tools award credits for building lifecycle elements including: the choice of building site and the ecology of that site (before, during and after construction), the choice of materials, design innovations that minimize resource use (e.g. water and energy) and reduce emissions (e.g. sewerage and refrigerants), and how a building integrates with other human and environmental services such as transport networks [11].

The recognition of a healthy, comfortable, and productive work environment is also an important element of these rating tools, usually captured as a dimension called indoor environmental quality [2]. Indoor environmental quality encourages building designers to incorporate features that will improve occupants' wellbeing and productivity through better use of daylight, external views, improved ventilation systems, more 'fresh' air and less recycled air, better light quality (e.g. reduced glare and flicker), noise reduction, better thermal comfort ranges, increased personal control of environmental conditions, and reduced toxins in the air (e.g. volatile organic compounds, formaldehyde, smoke, and other indoor pollutants). Within the LEED rating tool, an innovation credit can also be obtained for following good ergonomics design of the building interior as well as for introducing ergonomics training programmes [2]. This credit is not, however, available within the GreenStar rating tool used to evaluate the 'green' building in this study. Instead an innovation strategy credit was awarded in the GreenStar South Africa rating tool for investigating how productivity and occupant wellbeing would be influenced by a move to a 'green' building.

The inclusion of indoor environmental quality as a rating tool dimension is based on empirical research exploring the impact on health and performance appearing extensively in the environmental health [12-19], environmental engineering [20,21], environmental psychology [22-24], and environmental ergonomics [25-27] literature. Based on this body of literature it is widely believed (and in some cases actively promoted) that 'green' buildings are more comfortable, healthier, and produce higher levels of productivity than conventional buildings. However, Heerwagen and Zagreus [28] have noted that these claims have not always been consistently supported by empirical evidence. 


\subsection{Empirical evidence for occupant health and productivity in 'green' buildings}

Despite widespread claims for the superiority of 'green' buildings there are a limited number of detailed evaluations involving the impact on building occupants available in the public domain [29]. While empirical evidence for productivity gains in 'green' buildings is relatively well-established, the relationships for physical and psychological wellbeing emerge less clearly. Early case studies of green buildings produced consistent evidence that 'green' buildings increased productivity [30,31], reduced absenteeism [32], and improved building user satisfaction levels [31]. In one building [30] the claim was for a $28 \%$ increase in productivity. A more common claim is for productivity gains of under $10 \%$ [30,31]. More recently, support for the impact of 'green' buildings on productivity, while still generally favorable, is more mixed. Some studies have found no significant differences in perceived productivity [33] or absenteeism [33-36], while other studies have demonstrated increases in perceived productivity [27,37-39] or reduced absenteeism [36]. Generally, studies that report on improved productivity either use absenteeism as a proxy for productivity [35] or asked respondents to indicate how much their work environment has improved their productivity $[26,36]$. The most comprehensive study assessing productivity directly [40] found evidence for increased typing speed and lawyers' billing amounts, reduced absenteeism, but not self-reported productivity. Other than perceptions of the physical environment, only four studies could be found that examined the impact of a 'green' building on the psychological wellbeing or physical wellbeing of building occupants. Heerwagen [30] found that motivation, job satisfaction, emotional wellbeing and social wellbeing at work increased for daytime workers in a 'green' building. Paevere and Brown [35] reported that physical wellbeing in the 'green' building was high but provided no data on comparative measures of physical wellbeing. Thatcher and Milner [33] found no significant improvements for psychological wellbeing, physical wellbeing, job satisfaction, or propensity to stay in the organization in a 'green' building. Hedge and Dorsey [27] found evidence for positive perceptions of health and performance in two 'green' buildings but their study design did not allow statistical comparisons. No other studies could be found that examined the impact of a 'green' building on the physical and psychological wellbeing of building occupants despite the fact that Heerwagen [41] identified these aspects as important components in evaluating the organizational success of 'green' buildings.

Studies that have looked at user satisfaction with the physical environment generally find positive occupant satisfaction ratings for 'green' buildings [27, $30,38-40,42,43]$. However, studies have also consistently found that noise $[27,26,36,41,45]$, thermal comfort $[27,28,35,36,43,46]$, and lighting conditions [28, $33,35,37,45]$ were problematic in some 'green' buildings. Other studies have found that lighting was better $[31,36,38]$ or that air quality was better [39] but that the office temperature was problematic [36,38,39,43]. Thatcher and Milner [33] found in their study (in the same organisation as this current study) that the 'green' building was less noisy and thermal comfort was better but that lighting aspects were significantly worse. This lack of consistency in the results would suggest that there are some design aspects of 'green' buildings or some aspects of the work context that are more important in determining positive reactions to the physical environment. For example, Heerwagen [30] found significant differences between different groups of workers in satisfaction with the physical environment, but only for the office workers who worked during the day and not for shiftworkers. She found that respondents across-the-board felt overworked at the end of a work shift. Heerwagen [41] argued that "it's not how green you make it - it's what you make green" (p. 353). No studies have systematically evaluated which design aspects of 'green' buildings have the largest impact on occupant satisfaction levels.

Studies that draw comparisons between 'green' buildings also produce inconclusive results. Abbaszadeh et al. [37] for example compared 21 'green' buildings to 160 'non-green' buildings and found that users were most satisfied with thermal comfort and air quality, neutral on noise and lighting conditions (e.g. glare), and dissatisfied with light levels and privacy. Fowler and Rauch [43] examined 12 'green' buildings and found that while satisfaction with the indoor environment was generally high, satisfaction with noise levels and thermal comfort was lower than national benchmarks. The US Green Building Council [36] report examined 51 LEED-accredited buildings and found that these buildings were higher than the national average on satisfaction scores (especially on lighting) but lower than the national average for thermal comfort and noise. Leaman et al. [34] compared 22 'green' buildings to 23 conventional buildings and found that the 'green' buildings were rated sig- 
nificantly lower on thermal comfort, noise, and some lighting conditions (i.e. glare). Paul and Taylor [46] examined two 'non-green' buildings and a GreenStaraccredited building and found no significant differences on satisfaction ratings, except for thermal comfort where the 'green' building was perceived to be significantly warmer. Moschandreas and Nuanual [47] compared 20 LEED-certified buildings to 20 conventional buildings and concluded that the 'green' buildings were better than traditional buildings on four characteristics, the same on three characteristics, and worse on one characteristic. Unfortunately they did not provide details on which characteristics were different or the same.

\subsection{Methodological limitations of previous studies}

From a methodological perspective most of the studies only provide evaluations using a post-occupancy measure [27,35-37,43-46]. Only taking a postoccupancy measure tells us very little about what conditions were like before employees occupied the 'green' building. It could be that employees were already satisfied with building conditions before moving into a 'green' building or that productivity was already high. Some of the instruments ask respondents to draw comparisons with conditions from before the move to a 'green' building [28,34,44,45]. This is an approach which might be open to several psychological biases including memory and recency biases. Evans [12] called for more longitudinal designs in order to understand the relationships between people and their wellbeing responses to the built environment. To date, the only longitudinal studies reporting direct comparisons before and after a move to a 'green' building are Sustainability Victoria [40] and Thatcher and Milner [33]. There are other studies that have longitudinal components but which don't report both preand post-measures $[38,39,47]$ or do not give statistical comparisons even if the numerical values are provided [30].

Many of the studies do not include any comparison group at all [30,31,38-40] or draw comparisons with national benchmark databases [36-38,43,45] which may contain evaluations of buildings that are not comparable. Comparing 'green' buildings to conventional buildings (or national benchmarks) with only post occupancy measures $[35-37,43,44,46]$ may be meaningless because employees in different buildings may be in different organizations, working in different industries, and doing different types of work. For example,
Paul and Taylor [46] compared a 'green' building at one university with two 'green' buildings at another university. Differences in satisfaction ratings may have been due to the different organizational settings rather than a true reflection of the building. Only Paevere and Brown [35] and Thatcher and Milner [33] draw direct statistical comparisons between buildings in the same organization.

\subsection{Research aims}

Using a longitudinal, comparison group design, this study aimed to investigate if moving into a 'green' building improved productivity, psychological wellbeing, and physical wellbeing over working in a conventional building. In addition, this study also investigated whether perceptions of the physical working environment changed after moving into a 'green' building.

\section{Methods}

\subsection{The 'green' building}

The 'green' building under investigation was one of the first GreenStar-accredited buildings in South Africa. The 'green' building received a GreenStar fourstar rating of 52 credits (59 credits are required for a five-star GreenStar rating) and 17 (out of 27; i.e. 63\%) credits for the indoor environmental quality dimension. The indoor environmental quality aspects of the building included a ventilation system with a rate of fresh air intake $50 \%$ more than the national standard, a monitoring system for $\mathrm{CO}_{2}$ levels connected to the ventilation system, lighting systems that reduced flicker and were movement sensitive, exterior design features to reduce glare from the sun, interior paints and carpeting with reduced VOC levels, no formaldehyde was used, no PVC was used, and $60 \%$ of the office area had exterior views. In addition, other 'green' building design features included a rain water catchment system, indigenous landscaping, a building user's guide, a 30\% fly-ash component in cement for the building, and measures to encourage pedestrians and cyclists. The comparison buildings were two pre-existing office buildings which did not have a 'green' intent in their design. These buildings had air-conditioning systems but with no fresh air ventilation component and with no individual control of lighting or ventilation. These buildings were more than 30 years old and complied with local building legislation at that time but had no glare protection and no plant landscaping. 


\subsection{Procedures}

The study was conducted in a large financial institution with more than 10000 employees across the country. The new 'green' building could accommodate 600 staff members when fully occupied. The study design was longitudinal, with two groups: a treatment group where employees moved from existing buildings to the new 'green' building (i.e. the 'green' building group) and a contrast group where employees stayed in their existing building (i.e. the Other group). Time 1 data were collected from 2 December 2010 to 24 January 2011 shortly before any employees moved to the 'green' building on 1 February 2011. Time 2 data were collected approximately six months after the 'green' building group had moved to the 'green' building from 30 May to 12 June 2011. Time 3 data were collected approximately one year after the 'green' building group had moved to the 'green' building from 23 January to 10 February 2012. A total of 745 emails were sent to two randomly selected samples from each of these groups (roughly 375 employees from each group). The email consisted of a short covering note inviting participation and a hyperlink to the online version of the survey. Volunteer respondents completed the survey online and clicked on the submit button at the end of the survey. Clicking the submit button was considered as consent to participate. At Time 1 there were 212 completed responses returned ( $28 \%$ response rate). Six months later emails were sent to all 745 email addresses again. At Time 2 there were 121 completed responses returned (16\% response rate). At Time 3 (approximately twelve months after the first set of data were collected) the process was repeated and $111 \mathrm{com}-$ pleted responses were returned (15\% response rate). This drop-off in response rate was expected. Studies consistently demonstrate that there is a large drop-out rate of respondents for longitudinal studies and that this may be worse with online surveys [48]. Respondents were also asked to provide their employee number so that matching their responses at the three data collection points would be possible. At Time 2 there were 86 responses that could be matched to Time 1 (41\% of Time 1 respondents). At Time 3, 41 responses were received that could be matched to Time 2 and Time 1 (48\% of Time 2 respondents).

\subsection{Sample}

At Time 1 there were 98 (46\%) respondents from the 'green' building group and 114 (54\%) from the Other group. There were 51 (24\%) males and 159 (75\%) females in the sample. The respondents were from a range of different ethnic groups representative of this area of the country. The average age of the respondents was 37.12 years ( $\mathrm{SD}=8.73$ years) and had an average of 103.40 months (SD $=88.91$ months) working for the organization. Respondents were from a range of different seniority levels within the organization, although were predominantly administrative staff $(N=$ $119 ; 56 \%)$ and the smallest proportion of the sample was senior management $(N=4 ; 2 \%)$. There were 53 (25\%) respondents who indicated that they had at least one chronic underlying illness; mostly high blood pressure, asthma, cancer, a psychiatric disorder, or diabetes mellitus. At Time 2 there were 80 (66\%) respondents from the 'green' building group and 41 (34\%) from the Other group. The gender proportion remained similar (26\% males and $74 \%$ females) as did the proportional representation of ethnic groups. The average age was slightly higher $(40.50$ years; $\mathrm{SD}=8.90)$. The respondents were still predominately administrative staff $(51 \%)$ with a small proportion of senior management (4\%). At Time 3 there were 59 (54\%) respondents from the 'green' building group and 52 (46\%) from the Other group. The gender proportions (24\% males, $74 \%$ females) and ethnic group proportions again remained similar. The average age was slightly higher again ( 41.58 years; $\mathrm{SD}=9.44)$ and administrative staff still dominated the sample (49\%) although there were representative respondents from all seniority groups (e.g. 21\% lower management/supervisors; $25 \%$ middle management; $5 \%$ senior management). The matched sample was similar to the unmatched sample with regards to the demographic descriptors. There were 28 respondents in the 'green' building group and 13 respondents in the Other group. In comparison to the unmatched samples there were a similar proportion of male $(27 \%)$ and female $(73 \%)$ respondents and representative respondents from lower management (24\%), middle management $(27 \%)$, and senior management (7\%), but a slightly lower proportion of administrative staff $(39 \%)$. The age of respondents in the matched sample was slightly higher $(42.75$ years; $S D=9.11)$ as was the average length of time working for the organization (121.93 months; SD = 88.79). There were 11 (27\%) respondents reporting at least one chronic underlying illness.

\subsection{Measures}

The first part of the survey captured biographical information including age, gender, race, organizational 
level, tenure, and chronic underlying illness. In the second part of the survey the primary variables of interest were assessed. These measures, except for tenure and chronic underlying illness, were taken at each time point. The following quantitative measures were used.

Psychological wellbeing was assessed using the Warwick-Edinburgh Mental Well-Being Scale (WEMWBS) [49]. The WEMWBS is a 14-item scale with a 5 -point frequency scale assessed over the past month (i.e. none of the time, rarely, some of the time, often, all of the time). Tennant et al. [49] reported an internal consistency of 0.91 in a general population sample and good criterion-related validity. The internal reliability in this study ranged from 0.93 (Time 1 and 3) to 0.95 (Time 2).

Physical wellbeing was assessed using the Sick Building Syndrome (SBS) questions [50]. This is a set of 15 items that assess different physical well-being factors related to SBS on a 4-point frequency scale over the previous month (i.e. never, 1-3 times per month, 1-3 times per week, every day). The internal reliability in this study ranged from 0.90 (Time 1) to 0.93 (Time 2).

Perceptions of physical work conditions were assessed using 14 items taken from Hedge et al. [50]. Respondents were required to indicate the frequency of negative aspects of the work environment on a 4-point frequency scale over the previous month (i.e. never, 13 times per month, 1-3 times per week, every day). These were treated as individual items for analysis in this study.

Job satisfaction was assessed by a single item asking "Taking everything into consideration how do you feel about your job as a whole?" (from very dissatisfied to very satisfied). Wanous et al. [51] observed that single-item measures of job satisfaction were parsimonious and at least as good as multiple items in assessing global measures of job satisfaction.

Absenteeism was assessed by a single item taken from Biron et al. [52] asking "During the last 12 months, how many days sick leave have you taken?"

Presenteeism was assessed by a single item taken from Biron et al. [52] asking "During the last 12 months, how many days did your work despite being ill because you felt you had to?"

Perceived productivity was assessed on a single item asking "On a scale of 0-100 percent (where 100\% is full capacity), rate how well you have been working over the last month in relation to your full capacity."
Table 1

Average time spent in the building

\begin{tabular}{lccc}
\hline & Time 1 & Time 2 & Time 3 \\
\hline Hours in building per week: & & & \\
$\quad$ 'Green' building & 8.38 & 8.38 & 8.52 \\
$\quad$ Other buildings & 8.21 & 8.09 & 8.16 \\
$\quad$ Hours per week at work station: & & & \\
$\quad$ 'Green' building & 7.47 & 7.14 & 7.04 \\
$\quad$ Other building & 7.24 & 7.04 & 6.93 \\
$\quad$ & & & \\
Days per week in building: & 4.98 & 4.87 & 4.80 \\
$\quad$ Green' building & 5.11 & 4.92 & 5.00 \\
$\quad$ Other building & & & \\
\hline
\end{tabular}

\subsection{Analyses}

In the unmatched sample ANOVA's with Scheffe's post-hoc tests were used to test for significant differences across the three data collection points. Student's t-tests were used to examine differences between the 'green' building group and the Other group on each variable at each data collection point. Due to the small sample sizes and the significant differences in the normal distribution of the variables in the matched sample, Kruskal-Wallis tests were used to test for significant differences across the three data collection points and separate pair-wise Mann-Whitney U tests to compare the two groups at each data collection point.

\section{Results}

\subsection{Time spent in the buildings}

In order to determine the possible influence of the building/s on their occupants it was first necessary to determine how much time the respondents spent in their respective buildings. The number of hours per day spent in the building, the number of hours per day spent at their work station, and the number of days per week spent in the building is presented in Table 1. Both groups spent slightly longer than 8 hours per day in the building and around 7 hours per day at their work station. Both groups spent approximately 5 days per week in the building. None of the differences were statistically significant across data collection points or between the two groups at any data collection point. No significant differences were found on time spent in the building for the matched sample either.

\subsection{Wellbeing and productivity}

On the productivity measures the Other group was the only group that demonstrated a statistically sig- 
nificant improvement from Time 1 to Time 3. Absenteeism $(F=3.34 ; p<0.05)$ was significantly lower at Time 3. It is important to note that this may have been due to the fact that absenteeism was significantly higher in the Other group compared to the 'green' building group at Time $1(t=-2.90 ; p<0.01)$. The Other group was not significantly different at Time 2 or Time 3 although absenteeism in the Other group was always higher. A similar trend was noted for selfreported productivity which was statistically higher for the 'green' building group at Time $1(t=2.41 ; p<$ $0.05)$ but the difference had diminished to statistical non-significance by Time 2 and Time 3 despite always being higher. Presenteeism was also significantly lower for the 'green' building group at Time $2(t=-2.11$; $p<0.05$ ) but not at Time 1 or Time 3 despite being lower at each time point. The matched group produced a slightly different pattern for these productivity measures. While there were no statistically significant differences across the three data collection points for the Other group, the 'green' building group was significantly higher at Time 3 (compared to Time 1 and Time 2) on self-reported productivity $\left(X^{2}=6.01 ; p<\right.$ $0.05)$, moving from $83.29 \%$ at Time 1 , to $81.14 \%$ at Time 2, and $90.75 \%$ at Time 3 whereas the Other group showed a decline from $86.85 \%$ at Time 1 , to $88.38 \%$ at Time 2 , and $73.62 \%$ at Time 3 .

On the wellbeing measures, the Other group demonstrated significantly improved psychological wellbeing $(F=4.29 ; p<0.05)$, physical wellbeing $(F=$ 5.50; $p<0.01)$, and job satisfaction $(F=4.77 ; p<$ 0.01 ) from Time 1 to Time 3 in the unmatched sample whereas the 'green' building group only demonstrated significantly improved physical wellbeing $(F=3.80$; $p<0.01)$. At Time 1 the 'green' building group scored significantly higher on job satisfaction $(t=3.82 ; p<$ 0.01 ) but this difference was absent at Time 3 . At Time 3, the Other group had a significantly higher psychological wellbeing score $(t=-2.46 ; p<0.05)$ than the 'green' building group that was not present at Time 1. The averages and the significant differences across data collection points are summarized in Table 3 . The pattern was slightly different for the matched groups. Physical wellbeing $\left(X^{2}=6.63 ; p<0.05\right)$ was the only measure that was significantly higher for the 'green' building group and none of the measures were significantly different for the Other group.

\subsection{Perceptions of the physical work environment}

The results suggest that for both groups air quality demonstrated statistically significant improvements
Table 2

Productivity differences over the data collection points

\begin{tabular}{llccc}
\hline & Time 1 & Time 2 & Time 3 & Sign. \\
\hline Absenteeism (days per year): & & & & \\
'Green' building & 4.31 & 3.89 & 4.82 & NS \\
$\quad$ Other buildings & $6.49^{*}$ & 4.21 & 4.40 & $<0.05$ \\
Presenteeism (days per year): & & & & \\
'Green' building & 15.92 & 5.99 & 10.23 & NS \\
$\quad$ Other building & 23.07 & $25.95^{*}$ & 17.02 & NS \\
Self-reported productivity: & & & & \\
'Green' building & $82.80^{*}$ & 80.45 & 86.86 & NS \\
$\quad$ Other building & 74.67 & 79.63 & 79.94 & NS \\
\hline
\end{tabular}

${ }^{*}$ Significantly higher than the other group/s for that measure at that time point.

Table 3

Psychological and physical wellbeing differences over the data collection points

\begin{tabular}{lcccc}
\hline & Time 1 & Time 2 & Time 3 & Sign. \\
\hline $\begin{array}{l}\text { Psychological wellbeing: } \\
\text { 'Green' building }\end{array}$ & 3.51 & 3.57 & 3.58 & NS \\
$\quad \begin{array}{l}\text { Other buildings } \\
\text { Physical wellbeing: }\end{array}$ & 3.60 & 3.58 & $3.88^{*}$ & $<0.05$ \\
'Green' building & 3.07 & 3.24 & 3.28 & $<0.05$ \\
$\quad$ Other building & 2.99 & 3.10 & 3.32 & $<0.01$ \\
Job satisfaction: & & & & \\
'Green' building & $3.74^{*}$ & 3.58 & 3.58 & NS \\
$\quad$ Other building & 3.26 & 3.56 & 3.69 & $<0.01$ \\
$\begin{array}{l}\text { Propensity to stay in } \\
\text { the organization: }\end{array}$ & & & & \\
'Green' building & 3.52 & 3.41 & 3.43 & NS \\
$\quad$ Other building & 3.16 & 3.24 & 3.37 & NS \\
\hline
\end{tabular}

* Significantly higher than the other group/s for that measure at that time point.

across a number of components. For aspects of air movement, both groups improved significantly with the 'green' building group being significantly higher than the Other group, usually at Time 2; ventilation ('green building group: $F=10.63 ; p<0.01$; Other group: $F=9.79 ; p<0.01$; 'green' building significantly higher at Time $2: t=2.35 ; p<0.05$ ), not too drafty ('green' building group: $F=3.05$; $p<0.05$; Other group: $F=4.45 ; p<0.01$; 'green' building significantly higher at Time $2: t=1.99 ; p<0.05$ ), good air movement ('green' building group: $F=6.79$; $p<$ 0.01 ; Other group: $F=9.29 ; p<0.01$; 'green' building significantly higher at Time $2: t=2.92 ; p<0.01$ ), reduced humidity ('green' building group: $F=5.01$; $p<0.01$; Other group: $F=3.17 ; p<0.05$; 'green' building significantly higher at Time $1: t=3.58 ; p<$ 0.01 and Time 2: $t=4.27 ; p<0.01$ ), and non-stale air ('green' building group: $F=19.37$; $p<0.01$; Other group: $F=4.78 ; p<0.01$; 'green' building significantly higher at Time $2: t=4.15 ; p<0.01$ and Time 
Table 4

Air quality differences over the data collection points

\begin{tabular}{|c|c|c|c|c|}
\hline & Time 1 & Time 2 & Time 3 & Sign. \\
\hline $\begin{array}{l}\text { Sufficient ventilation: } \\
\text { 'Green' building } \\
\text { Other building }\end{array}$ & $\begin{array}{l}2.89 \\
2.77\end{array}$ & $\begin{array}{l}3.58^{*} \\
3.17\end{array}$ & $\begin{array}{l}3.26 \\
3.54\end{array}$ & $\begin{array}{l}<0.01 \\
<0.01\end{array}$ \\
\hline $\begin{array}{l}\text { Not too drafty: } \\
\text { 'Green' building } \\
\text { Other building }\end{array}$ & $\begin{array}{l}3.40 \\
3.28\end{array}$ & $\begin{array}{l}3.38^{*} \\
2.98\end{array}$ & $\begin{array}{l}3.74 \\
3.56\end{array}$ & $\begin{array}{l}<0.05 \\
<0.01\end{array}$ \\
\hline $\begin{array}{l}\text { Good air movement: } \\
\text { 'Green' building } \\
\text { Other building }\end{array}$ & $\begin{array}{l}2.96 \\
2.72\end{array}$ & $\begin{array}{l}3.49^{*} \\
2.95\end{array}$ & $\begin{array}{l}3.33 \\
3.46\end{array}$ & $\begin{array}{l}<0.01 \\
<0.01\end{array}$ \\
\hline $\begin{array}{l}\text { Not too dry: } \\
\text { 'Green' building } \\
\text { Other building }\end{array}$ & $\begin{array}{l}3.23 \\
3.16\end{array}$ & $\begin{array}{l}3.53 \\
3.30\end{array}$ & $\begin{array}{l}3.46 \\
3.62\end{array}$ & $\begin{array}{c}\text { NS } \\
<0.01\end{array}$ \\
\hline $\begin{array}{l}\text { Not too humid: } \\
\text { 'Green' building } \\
\text { Other building }\end{array}$ & $\begin{array}{l}3.59^{*} \\
3.17\end{array}$ & $\begin{array}{l}3.89^{*} \\
3.39\end{array}$ & $\begin{array}{l}3.72 \\
3.51\end{array}$ & $\begin{array}{l}<0.01 \\
<0.05\end{array}$ \\
\hline $\begin{array}{l}\text { No stale air: } \\
\text { 'Green' building } \\
\text { Other building }\end{array}$ & $\begin{array}{l}3.08 \\
2.86\end{array}$ & $\begin{array}{l}3.75^{*} \\
3.15\end{array}$ & $\begin{array}{l}3.67^{*} \\
3.35\end{array}$ & $\begin{array}{l}<0.01 \\
<0.01\end{array}$ \\
\hline $\begin{array}{l}\text { No unpleasant odour: } \\
\text { 'Green' building } \\
\text { Other building }\end{array}$ & $\begin{array}{l}3.34^{*} \\
2.79\end{array}$ & $\begin{array}{l}3.55 \\
3.28\end{array}$ & $\begin{array}{l}3.36 \\
3.33\end{array}$ & $\begin{array}{c}\mathrm{NS} \\
<0.01\end{array}$ \\
\hline
\end{tabular}

* Significantly higher than the other group/s for that measure at that time point.

$3: t=2.25 ; p<0.01)$. The marked improvements in non-stale air are not surprising given the emphasis on a fresh air component to the ventilation system and the use of $\mathrm{CO}^{2}$ monitors. However, for dryness and odours in the air the Other group displayed statistically significant improvements over time whereas the 'green' building group did not. For the air not being too dry the Other group was statistically significantly higher $(F=$ 4.86; $p<0.01)$ at Time 3. For the lack of unpleasant odours in the air the Other building showed significant improvements $(F=8.49 ; p<0.01)$ for Time 2 and Time 3. This is notable given that the 'green' building group was also significantly higher than the Other group at Time 1 ( $t=4.50 ; p<0.01)$. This is unusual given the emphasis on low VOC paints and adhesives in the 'green' building, but it is possible that these alternative products may still have produced a smell that was perceived as unpleasant. These results are summarized in Table 4.

For the matched groups the 'green' building group was significantly higher than Time 1 at Time 2 and Time 3 on the following aspects: sufficient ventilation $\left(X^{2}=18.39 ; p<0.01\right)$, good air movement $\left(X^{2}=\right.$ 9.43; $p<0.01)$, not too dry $\left(X^{2}=6.00 ; p<0.05\right)$, not too humid $\left(X^{2}=6.19 ; p<0.05\right)$, and no stale air $\left(X^{2}=11.06 ; p<0.01\right)$. No statistically significant differences were found for any of these aspects in the
Table 5

Other physical ambient conditions - differences over the data collection points

\begin{tabular}{llllc}
\hline & Time 1 & Time 2 & Time 3 & Sign. \\
\hline $\begin{array}{c}\text { Lighting not too dim: } \\
\text { 'Green' building }\end{array}$ & 3.60 & 3.18 & 3.14 & $<0.01$ \\
Other building & 3.56 & $3.68^{*}$ & $3.69^{*}$ & $\mathrm{NS}$ \\
Not too much glare: & & & & \\
'Green' building & 3.28 & 3.51 & 3.56 & $\mathrm{NS}$ \\
$\quad$ Other building & 3.43 & 3.56 & 3.58 & $\mathrm{NS}$ \\
Not too noisy: & & & & \\
'Green' building & 2.75 & 2.86 & 2.88 & $\mathrm{NS}$ \\
Other building & 2.65 & 2.75 & 2.92 & $\mathrm{NS}$ \\
Not too dusty & & & & \\
'Green' building & 3.17 & $3.75^{*}$ & $3.67^{*}$ & $<0.01$ \\
Other building & 3.01 & 3.15 & 3.35 & $<0.05$ \\
No static shocks: & & & & \\
'Green' building & 3.42 & $3.80^{*}$ & 3.81 & $<0.01$ \\
Other building & 3.46 & 3.39 & 3.76 & $\mathrm{NS}$ \\
Not too warm: & & & & \\
'Green' buildings & 3.10 & 3.26 & 3.00 & $\mathrm{NS}$ \\
Other buildings & 2.88 & $3.18^{*}$ & $3.26^{*}$ & $<0.05$ \\
Not too cold: & & & & \\
'Green' building & 2.15 & 2.15 & $2.69^{*}$ & $<0.01$ \\
Other buildings & 2.12 & 2.12 & 2.40 & $\mathrm{NS}$ \\
\hline
\end{tabular}

* Significantly higher than the other group/s for that measure at that time point.

Other group. The 'green' building group was significantly higher than the Other group on good air movement $(p=0.03)$, no stale air $(p=0.02)$, reduced humidity $(p=0.03)$, and not too drafty $(p=0.02)$ at Time 2 only.

The most definitive response from the other office ambient conditions was that the lighting conditions were perceived to be significantly more dim in the 'green' building group $(F=6.45 ; p<0.01)$. While the facilities management experienced commissioning problems with the lighting which might explain the significantly lower perceptions of the lighting at Time $2(t=2.94 ; p<0.01)$ this perception persisted at Time $3(t=3.49 ; p<0.01)$ when the lighting was fully commissioned. A similar pattern emerged for a lack of dustiness (not a surprising finding given that the 'green' building was new and had not had time to accumulate much dust) where the 'green' building group demonstrated significant improvements $(F=$ 5.83; $p<0.01)$ over time and was significantly higher than the Other group at Time $2(t=4.15 ; p<0.01)$ and Time $3(t=2.25 ; p<0.05)$ although for this aspect the Other group also demonstrated improvement over time $(F=4.13 ; p<0.01)$. Similarly, the 'green' building group demonstrated statistically fewer electrostatic shocks $(F=8.61 ; p<0.01)$ over time and was significantly higher than the Other group at Time 2 
$(t=3.17 ; p<0.01)$. The Other group did not demonstrate statistically significant improvements over time for this measure. With respect to the temperature conditions the Other group showed significant improvements from Time 1 to Time 3 on the perception that the building environment was not too warm $(F=4.29$; $p<0.05$ ) whereas the 'green' building group showed significant improvements from Time 1 to Time 3 and from Time 2 to Time 3 that the building environment was not too cold $(F=5.91 ; p<0.01)$. No significant improvements were found for either group on glare and noise reduction. The lack of significant findings for the glare aspect was surprising given that the building was designed with glare reduction measures. These results are summarized in Table 5.

The matched groups again provided a clearer view of these ambient conditions. The 'green' building group was significantly lower on the dim lighting question $\left(X^{2}=9.20 ; p<0.05\right)$ at Time 2 and Time 3 and was significantly higher on the reduction in electrostatic shocks $\left(X^{2}=8.89 ; p<0.05\right)$ at Time 2 and Time 3. No statistically significant differences were found for the Other group on any aspect. The 'green' building group was significantly lower than the Other group demonstrating the perception of dimmer lighting conditions at Time $2(p=0.03)$ and Time $3(p=$ $0.001)$. The 'green' building group also experienced statistically fewer electrostatic shocks at Time 1 ( $p=$ 0.02).

\section{Discussion}

\subsection{Discussion of the results}

The results for the productivity variables did not provide a consistent pattern of improvements for the 'green' building group. On the matched sample, selfreported productivity for the 'green' building was significantly higher at Time 3 compared to Time 1 (increasing by approximately $7 \%$ from before the move when the Other group decreased by approximately $13 \%$ over the same time period) but not for absenteeism or presenteeism. This result for the matched group supports the findings of the majority of previous research [28,30,37-39] and specifically Romm and Browning's [31] findings of just under $10 \%$ improvement in productivity. For the unmatched sample, absenteeism decreased significantly for the Other group (although absenteeism was always lower in the 'green' building group) while presenteeism decreased signifi- cantly for the 'green' building group, but only at Time 2. Sustainability Victoria [40] also found significant improvements in a smaller sub-sample (5 typists and 12 lawyers) using 'hard' measures of productivity (e.g. typing speed and lawyers' billings) but not on the measure of self-reported productivity. None of the productivity measures used in the current study were independent measures of productivity or performance but only self-reports of productivity, absenteeism, and presenteeism. Heerwagen [30] noted that most organizations experience a drop in productivity when workers move. This would imply that even if productivity measures remain similar despite a major organizational intervention, such as a change in office building, this might actually be a positive indicator.

For the unmatched and the matched samples, psychological wellbeing did not significantly improve in the 'green' building group. Instead, psychological wellbeing and job satisfaction increased significantly over the study period in the Other group, but for the unmatched sample only. The lack of improvement in psychological wellbeing in the 'green' building is consistent with Thatcher and Milner [33] but not with Heerwagen [30], although she did not test for statistical significance and did not have a contrast group (i.e. a group that did not move into a 'green' building). The significant improvement in physical wellbeing was consistent across the matched and unmatched samples, although was also significantly higher in the unmatched sample for the Other group. These results support those of Hedge and Dorsey [27] who also found perceived improvement in physical wellbeing in their two 'green' buildings. Improvements in perceptions of physical wellbeing are also likely to translate into improvements in psychological wellbeing and productivity over time (especially absenteeism and presenteeism), provided the improvements are maintained. Only Thatcher and Milner [33] provided comparisons of perceived physical wellbeing in a 'green' building (other than through absenteeism) and they found no significant improvements. Paevere and Brown [35] reported that physical wellbeing in a 'green' building was largely symptom-free but did not examine any preand post-occupancy changes in physical wellbeing.

It is quite difficult to draw comparisons between the results of this study and previous investigations because of the variety of 'green' building designs and research designs used to investigate their impact on building occupants. Nevertheless, the reduced efficacy of the lighting conditions $[28,35,37,45]$ and increased perceptions of the air quality $[39,46]$ are con- 
sistent findings in previous studies. Artificial lighting in 'green' buildings is often reduced to provide energy savings and this may mean that the interiors of 'green' buildings are perceived as dimmer compared to conventional buildings that are frequently over lit. Improvements in thermal comfort (specifically not being too warm) are also a consistent findings from previous research $[28,35,36,43,46]$. It is important to note that with the exception of reduced stale air, the significant improvements occurred predominantly only at Time 2 rather than Time 3 . The Time 2 data collection point was in winter suggesting that this particular 'green' building's design features equalized indoor environmental quality across the year and the benefits were therefore most prevalent in this season. The improvement in reduced stale air is unsurprising given that the building design incorporates a large fresh air component and $\mathrm{CO}$ monitors. Electrostatic shocks were also significantly reduced in the 'green' building group both at Time 2 and Time 3. The perceptions of the physical environment were not always positive in the 'green' building. Notably the 'green' building group in the unmatched sample perceived the air to by significantly drier at Time 3 and unpleasant odours were more prevalent at Time 2 and Time 3 .

\subsection{General discussion}

The results provide suggestive, but not conclusive, evidence that 'green' buildings may have positive wellbeing and effectiveness benefits for building occupants over conventional buildings. This result is more clearly seen in the matched sample (which is arguably a more robust study design, albeit on a small sample). However, as suggested by Heerwagen and Zagreus [28] the results do not provide compelling support for claims by 'green' building councils that 'green' buildings are healthier and more productive. This should not be interpreted as a motivation to place less emphasis on indoor environmental quality in 'green' building designs. Instead, this should be seen as an incentive for further investigation to determine which elements of indoor environmental quality and 'green' building design have the best likelihood to positively influence occupant wellbeing and productivity. The reasons for the inconsistencies in results across studies (and in this study) are probably due to methodological issues, the local climatic conditions (including the season when evaluations are made), and to design differences between buildings. The methodological issues were covered more extensively in the earlier review of the liter- ature where it was argued that most studies lack preoccupancy measures to determine change effectively and do not have relevant comparison groups to control for extraneous contextual variables. Hedge and Dorsey [27] also propose that many of the performance and wellbeing benefits are not realised in 'green' buildings because of a failure to address ergonomics concerns, such as eyestrain from computer workstations where the prevalence is comparable to conventional buildings.

Second, most 'green' buildings do not adopt all the design features that have been shown in the literature to independently promote wellbeing and effectiveness. 'Green' building designs involve a choice of design elements based on cost, the local climatic conditions, integration with other design elements such as geographical position and proximity to other buildings, and the preferences of the architects, engineers, developers, and occupants. Even if important 'green' building design features are incorporated into the building design this does not guarantee that they will be commissioned properly by facilities managers (e.g. the lighting was not properly commissioned immediately after occupation in the current study) or that building occupants will use the design features as intended [6, 7]. Certainly ergonomics is interested in the actual use of designs, not only on the designs themselves. As Attiainese [6] and Miller et al. [7] have suggested, ergonomics could play an important role in evaluating how 'green' buildings are used by their occupants. While a Building Users' Guide was developed for this 'green' building it is uncertain how many of the respondents had read (and understood) this guide. With regards to facilities managers, Lee and Kang [53] noted that the complexity of working with 'green' buildings was stumbling block. Facilities managers express uncertain and clearly require further training in how to operate 'green' buildings. Further, Kellert [54] refers to 'green' building specifications as being "low environmental impact design" (p. 120) that may lead to reduced environmental impact but not necessarily to "enhancing and restoring positive contact between people and nature [that] can foster human well-being and productivity" (p. 122). From this we suggest that 'green' building specifications require refinement (or broadening) to focus on those qualities that lead to improved physical and psychological wellbeing and productivity gains.

\subsection{Limitations and directions for future research}

Despite the more rigorous research design employed in this study there are still a number of limitations 
that require noting. First, this study reports on a single 'green' building in one organization. Given different local climatic conditions, the specific architectural design, and organizational culture issues it may be difficult to generalize to other buildings in other organizations. Second, the sample size, especially in the matched group, was relatively small (although reasonable for a longitudinal study over a period of one year). Other studies have reported on results using similarly small numbers: [24] $(N=77)$, [27] $(N=$ 44), [35] $(N=26)$, [36] $(N=24)$, and [42] $(N=$ $81)$. The matched sample consisted of only 41 respondents (and only 13 respondents in the Other group). While the study design is tight, the sample size is simply too small to make generalizations to the larger population. Future research should look to gather larger sample sizes so that more robust data analytical methods, such as repeated measures ANOVA, might be applied. The unmatched sample suffers from the limitation that each time point is essentially an independent sample. It is therefore difficult to establish confidence in comparisons between the time points. Third, as shown in the results, it is often difficult to compare time points because of changing seasons. It is possible that different times of year may mask any real underlying differences (e.g. the end of the year holidays versus the middle of year colds) or that differences may be due to fluctuations in weather conditions (e.g. too cold in Winter and too hot in Summer). The most robust comparisons in this study are therefore Time 1 to Time 3 given the similar times of year. Finally, it is not certain how long it would take for building design components to filter through to impact on wellbeing and productivity. Sustainability Victoria [40] found several significant improvements only three months post-occupation, while Heerwagen [30] suggested that her analysis nine months later was probably not long enough. In this study data were collected six months and twelve months post-occupation. The largest number of significant differences were noted six months later, although this might have been due to the different seasons. It may be that a longer duration is required to detect significant differences in long-term effects such as productivity and wellbeing.

There is a great deal of scope for ergonomics to play a role in uncovering which aspects of 'green' building design have the greatest (short term and long term) impact on employee health, wellbeing, satisfaction, and productivity. The current research findings suggest that improved air quality, particularly fresh air and $\mathrm{CO}_{2}$ monitors, is likely to have had the biggest impact. It is also suggested that it is not only the indoor environmental quality that plays a role in improved wellbeing and productivity but also the ergonomic design of interior spaces [2,27]. Hedge [2] argued for the inclusion of the ergonomic design of office workspaces, the use of ergonomic guidelines for office equipment, and ergonomics training. Leaman [55] proposed that rapid responses to conditions (i.e. personal control), discomfort alleviation, reductions in technological complexity, appropriate occupation density were the key factors in ensuring employee wellbeing and productivity in buildings. Heerwagen and Hase [56] add to this list by suggest that designers should focus on biophilic design (i.e. design that connects humans to nature). There is a growing body of literature supporting the idea that the incorporation of nature into our built environment has positive wellbeing benefits $[57,58]$ and results in higher productivity [59-61]. This might involve designing buildings where windows give natural daylight and views to natural landscapes, gathering places outdoors, and the inclusion of nature inside buildings [59]. Finally, the literature could benefit from more comprehensive investigations of the benefits of 'green' buildings that use a more controlled research design (i.e. contrast groups and longitudinal designs that include pre- and post-occupancy evaluations).

\section{References}

[1] Thatcher A. Green ergonomics: definition and scope. Ergonomics, 2013, 56(3): 389-398.

[2] Hedge A. The sprouting of "green" ergonomics. HFES Bulletin, 2008, 51(12): 1-3.

[3] Hanson M. Green ergonomics: embracing the challenges of climate change. The Ergonomist, 2010, 480: 12-13.

[4] Steimle U, Zink KJ. 2006. Sustainable development and human factors. In: Karwowski, W, editor. International encyclopedia of ergonomics and human factors. 2nd ed. London: Taylor and Francis; 2006. 2258-2263.

[5] Thatcher A. Early variability in the conceptualisation of "sustainable development and human factors". WORK: A Journal of Prevention, Assessment and Rehabilitation, 2012, 41: 3892-3899.

[6] Attiainese E. A broader consideration of human factors to enhance sustainable building design. WORK: A Journal of Prevention, Assessment and Rehabilitation, 2012, 41: 21552159.

[7] Miller L, Dorsey J, Jacobs K. The importance of ergonomics to sustainability throughout a building's life cycle. WORK: A Journal of Prevention, Assessment and Rehabilitation, 2012, 41: 2129-2132.

[8] Attiainese E, Duca G. The human component of sustainability: a study for assessing "human performances" of energy efficient construction blocks. WORK: A Journal of Prevention, Assessment and Rehabilitation, 2012, 41: 2141-2146. 
[9] Castañon JAB, Caldeira LFD, Gervásio MF, Brum FM. Critical analysis about solutions and models of solar shades in nonresidential buildings from tropical regions. WORK: A Journal of Prevention, Assessment and Rehabilitation, 2012, 41: 5422-5424.

[10] US Environmental Protection Agency. Green building, basic information, 2010. Available from http://www.epa.gov/ greenbuilding/pubs/about.htm [accessed July 2012].

[11] Gowri K. Green building rating systems: an overview. ASHRAE Journal, 2004, 46(11): 56-60.

[12] Evans GW. The built environment and mental health. Journal of Urban Health: Bulletin of the New York Academy of Medicine, 2003, 80(4): 536-555.

[13] Fisk WJ, Rosenfeld AH. Estimates of improved productivity and health from better indoor environments. Indoor Air, 1997, 7(3): 158-172.

[14] Myatt, TA, Johnston SL, Zuo Z, Wand M, Kebadze T, Rudnick S, Milton DK. Detection of airborne rhinovirus and its relation to outdoor air supply in office environments. American Journal of Respiratory and Critical Care Medicine, 2004, 169(11): 1187-1190.

[15] Northridge ME, Sclar ED, Biswas P. Sorting out the connections between the built environment and health: a conceptual framework for navigating pathways and planning healthy cities. Journal of Urban Health: Bulletin of the New York Academy of Medicine, 2003, 80(4): 556-568.

[16] Preziosi P, Czernichow S, Gehanno P, Hercberg S. Workplace air-conditioning and health services attendance among French middle-aged women: a prospective cohort study. International Journal of Epidemiology, 2004, 33(5): 1120-1123.

[17] Schweitzer M, Gilpin L, Frampton S. Healing spaces: elements of environmental design that make an impact on health. Journal of Alternative and Complementary Medicine, 2004, 10 (S1): S71-S83.

[18] Seppänen O, Fisk WJ , Lei QH. Ventilation and performance in office work. Indoor Air Journal, 2006, 16(1): 28-36.

[19] Ulrich RS. A view through a window may influence recovery from surgery. Science, 1984, 224(4647): 420-421.

[20] Heschong L, Wright RL, Okura S. Daylighting impacts on human performance in school. Journal of the Illuminating Engineering Society, 2002, 31(2), 101-114.

[21] Smedje G, Norback D. New ventilation systems at select schools in Sweden - effects on asthma and exposure. Archives of Environmental Health, 2000, 35(1): 18-25.

[22] Boubekri M, Hull RB, Boyer LL. Impact of window size and sunlight penetration on office workers' mood and satisfaction: A novel way of assessing sunlight. Environment and Behavior, 1991, 23(4): 474-493.

[23] Parsons R. The potential influences of environmental perception on human health. Journal of Environmental Psychology, 1991, 11(1): 1-23.

[24] Stone NJ, Irvine JM. Direct or indirect window access, task type, and performance. Journal of Environmental Psychology, 1994, 14(1): 57-63.

[25] Begemann SHA, van den Beld GJ, Tenner AD. Daylight, artificial light and people in an office environment, overview of visual and biological responses. International Journal of Industrial Ergonomics, 1997, 20(3): 231-239.

[26] Hedge A. Where are we in understanding the effects of where we are? Ergonomics, 2000, 43(7): 1019-1029.

[27] Hedge, A, Dorsey J. Green buildings need good ergonomics. Ergonomics, 2013, 56(3): 492-506.

[28] Heerwagen JH, Zagreus L. The human factors of sustainable building design: post occupancy evaluation of the Phillip Merrill Environmental Center, 2005, available from: www.wbdg.org/pdfs/human_factors_cbf.pdf [accessed August 2011].

[29] Birt B, Newsham GR. Post-occupancy evaluation of energy and indoor environment quality in green buildings: a review. Third International Conference on Smart and Sustainable Built Environments, Delft, Netherlands; June 15-19, 2009. p. 1-7.

[30] Heerwagen JH. Do green buildings enhance the well being of workers? Environmental Design + Construction Magazine, 2001, 2 (July/August): 24-30.

[31] Romm JJ, Browning WD. Greening the building and the bottom line. Snowmass: Rocky Mountain Institute; 1994.

[32] Browning WD. NMB Bank Headquarters: the impressive performance of a green building. Urban Land, 2002, June: 23-25.

[33] Thatcher A, Milner K. The impact of a 'green' building on employees' physical and psychological wellbeing. WORK: A Journal of Prevention, Assessment and Rehabilitation, 2012, 41: 3892-3899.

[34] Leaman A, Thomas L, Vandenberg M. 'Green' buildings: what Australian building users are saying. EcoLibrium, 2007, November: 22-31.

[35] Paevere P, Brown S. Indoor environment quality and occupant productivity in the $\mathrm{CH} 2$ building: post-occupancy summary, 2008, CSIRO. Available from http://melbourne.vic. gov.au/Environment/CH2/Evaluation/Documents/CH2_Post_ Occupancy_Summary.doc [accessed August 2011].

[36] US Green Building Council - Illinois Chapter. Regional green building case study: year two report, 2011. Available from: http://www.usgbc-illinois.org/resources/regionalgreen-building-case-study-project/ [accessed July 2012].

[37] Abbaszadeh S, Zagreus L, Lehrer D, Huizenga C. Occupant satisfaction with indoor environmental quality in green buildings Proceedings of Healthy Buildings, Lisbon, Vol. III, 2006. 365-370.

[38] Thomas LE. Evaluating design strategies, performance and occupant satisfaction: a low carbon office refurbishment. Building Research and Information, 2010, 38(6): 610-624.

[39] Thomas LE, Vandenberg M. 40 Albert Road, South Melbourne: designing for sustainable outcomes. BEDP Environmental Design Guide, 2007, May, Cas 45. Available from: http://www.environmentdesignguide.com.au/media/CAS45. pdf [accessed July 2012].

[40] Sustainability Victoria. Employee productivity in a sustainable building: pre- and post-occupancy studies in 500 Collins Street, 2006. Available from: www.resourcesmart. vic.gov.au/.../500_Collins_Productivity_Study.pdf [accessed August 2011].

[41] Heerwagen JH. Green buildings, organizational success, and occupant productivity. Building Research and Information, 2000, 28(5), 353-367.

[42] Baird G. Sustainable buildings in practice: what the users think. New York: Routledge; 2010.

[43] Fowler KM, Rauch GM. Assessing green building performance: a post-occupation evaluation of 12 GSA buildings. US General Services Administration Report, 2008. Available from: www.gsa.gov/graphics/pbs/GSA_Assessing_ Green_Full_Report.pdf [accessed August 2011].

[44] Thomas LE, Baird G. Torrent Research Centre, Ahmedabad, Gujarat, India. In: Baird G, editor. Sustainable buildings in practice: what the users think. New York: Routledge; 2010. p. 313-323.

[45] Bunn R. Tales from the Rivergreen. BSRIA Delta T, 2007: 12-16. 
[46] Paul WL, Taylor PA. A comparison of occupant comfort and satisfaction between a green building and a conventional building. Building and Environment, 2008, 43(11): 18581870.

[47] Moschandreas, DJ, Nuanual RM. Do certified sustainable buildings perform better than similar conventional buildings? International Journal of Environment and Sustainable Development, 2008, 7(3): 276-292.

[48] Sax LJ, Gilmartin SK, Bryant AN. Assessing response rates and nonresponse bias in web and paper surveys. Research in Higher Education, 2003, 44(4): 409-432.

[49] Tennant R, Hiller L, Fishwick R, Platt S, Joseph S, Weich S, Parkinson J, Secker J, Stewart-Brown S. The WarwickEdinburgh Mental Well-being Scale (WEMWBS): development and UK validation. Health and Quality of Life Outcomes, 2007, 5: 63.

[50] Hedge A, Erickson WA, Rubin G. Predicting sick building syndrome at the individual and aggregate levels. Environment International, 1996, 22(1), 1996: 3-19.

[51] Wanous JP, Reichers AE, Hudy MJ. Overall job satisfaction: how good are single-item measures. Journal of Applied Psychology, 1997, 82(2): 247-252.

[52] Biron C, Brun J, Ivers H, Cooper CL. At work but ill: psychosocial work environment and well-being determinants of presenteeism propensity. Journal of Public Mental Health, 2006, 5(4): 26-37.

[53] Lee SY, Kang M. Innovation characteristics and intention to adopt sustainable facilities management practices. Ergonomics, 2013, 56(3): 480-491.

54] Kellert SR. Building for life: designing an understanding the human-nature connection. Washington: Island press; 2005.

[55] Leaman A. Human factors: the bottom line. EcoLibrium, 2009, December: 36-38.

[56] Heerwagen JH, Hase B. Building biophilia: connecting people to nature in building design. Environmental Design + Construction Magazine, 2001, 3(March/April): 30-36.

[57] Kaplan R. The role of nature in the context of the workplace. Landscape and Urban Planning, 1993, 26(1): 193-201.

[58] Largo-Wight E, Chen WW, Dodd V, Weiler R. The Nature Contact Questionnaire: a measure of healthy workplace exposure. WORK: A Journal of Prevention, Assessment and Rehabilitation, 2011, 40(4): 411-423.

[59] Lohr VI, Pearson-Mims CH, Goodwin GK. Interior plants may improve worker productivity and reduce stress in a windowless environment. Journal of Environmental Horticulture, 1996,14(2): 97-100.

[60] Tennessen CM, Cimprich B. Views to nature: affects on attention. Journal of Environmental Psychology, 1995, 15(1): 77-85.

[61] Wyon DP. Enhancing productivity while reducing energy use in buildings. Proceedings of the E-Vision 2000 Conference, October 11-13, 2000, Washington, D.C., Rand Corporation: Arlington. 